\title{
Article
}

\section{Expertise and Choice: Both-And, Not Either-Or}

Downe, S

Available at http://clok.uclan.ac.uk/12424/

Downe, S ORCID: 0000-0003-2848-2550 (2015) Expertise and Choice: BothAnd, Not Either-Or. International Journal of Childbirth, 5 (3). pp. 114-115.

It is advisable to refer to the publisher's version if you intend to cite from the work.

For more information about UCLan's research in this area go to

http://www.uclan.ac.uk/researchgroups/ and search for < name of research Group>.

For information about Research generally at UCLan please go to http://www.uclan.ac.uk/research/

All outputs in CLoK are protected by Intellectual Property Rights law, including Copyright law. Copyright, IPR and Moral Rights for the works on this site are retained by the individual authors and/or other copyright owners. Terms and conditions for use of this material are defined in the policies page.

\section{CLoK}

Central Lancashire online Knowledge www.clok.uclan.ac.uk

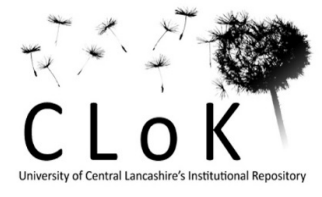




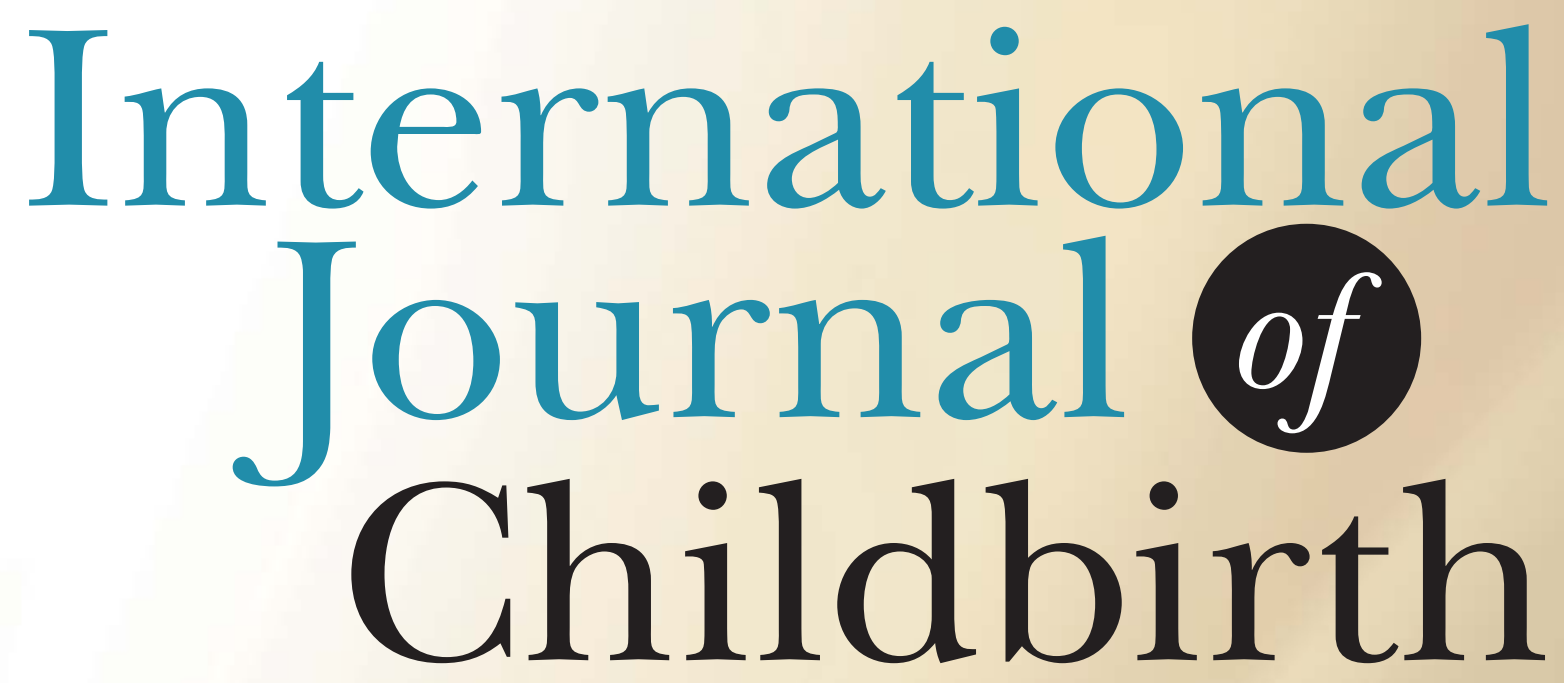

Official Publication of the International Confederation of Midwives 


\section{Expertise and Choice: Both-And, Not Either-Or}

Three of the articles in the current edition of the journal (Jefford \& Jomeen, 2015; Kabakian-Khasholian, Shayboub, Kanaan, Mahfoud, \& El Kak, 2015; Young, Smythe, \& Couper, 2015) brought me back to an issue that has been of interest to me for some time-that of the potential tension between choice and expertise. Who should make decisions about (non)treatment-the person who is affected directly or the person(s) whose expertise they have sought? It might be argued that this question is based on a framing error. The answer is not one or the other, but both, as in partnership models of care. Yes... but...

One of the key components of the choice agenda is to provide information to service users. However, the study by Kabakian-Khasholian and colleagues (2015) from Lebanon illustrates that, in contexts where there are clear societal power imbalances between service users and professionals, provision of information may only work alongside the provision of communication negotiation skills to those seeking to make effective personal choices. These skills are necessary to enable service users to feel confident enough to catch the attention of, and potentially to challenge, health care providers. When health carer expertise is unquestioned, to the extent where professionals are not held accountable for mistakes and for lack of evidence-based practice, any move toward mutually respectful decision making requires some basic steps toward redressing the balance of power, as shown by the data presented in the study.

On the other hand, in the settings for both the Jefford and Jomeen (2015) and the Young et al. (2015) studies, there appears to be a steady undermining of the notion of expertise in general, and of expert health care provision specifically. In these contexts, evidence-based medicine has been translated into scientific bureaucratic management. As many have noted previously, this leads to co-option of the risk and safety agenda, resulting in clinical decisions based on rules to be followed to prevent disciplinary action/litigation, where such practice rules become ends in themselves, rather than tools to be used flexibly to ensure the well-being of service users and staff. As a consequence, health professionals are losing both self-confidence and the capacity and courage to make difficult decisions based on expert knowledge and the wisdom of reflective experience, as is illustrated in the Jefford and Jomeen (2015) article in this edition.

A novice to expert taxonomy was proposed for nursing by Benner (2004), based on a prior study of skills acquisition across a range of professional groups (Dreyfus \& Dreyfus, 1980). This provides a stark insight into a steady move down the expertise hierarchy among health professionals in general.

Characteristics of the novice practitioner in the skills acquisition taxonomy include

- No experience

- Need rules

- Rules applied universally

- Rule-governed behavior limited and inflexible

- "Just tell me what I need to do, and I'll do it."

To me, some of the examples in the article by Jefford and Jomeen (2015) look remarkably like this kind of behavior. This is not just exemplified in, for instance, the midwife who prioritized attending a ward hand over above accompanying a laboring woman because he felt, at the time, that this was what the organization expected of him. Rather more controversially, I would see the examples of what the authors have termed Midwifery Abdication as demonstrating similar characteristics. In the examples given in the article, the midwives seem to have taken on a novice role through the adoption of the mantra of "woman-centered care" as a kind of rule, translated as "keeping the woman away from the system at all costs is in her (and her baby's) best interest." This seems to be occurring even when expert judgment would suggest that, in some specific cases, discussion with the woman and sharing of explicit expert advice might have resulted in an effective intervention that would have been both accepted by the woman and in the best interest of her/her baby. 
There are of course wider cultural and societal pressures that underpin this state of affairs. One of them is the notion of individual entitlement that underpins postmodern societies, along with an expectation of perfection. In itself, this could be driven by the core assumption of scientific bureaucracy that all errors can be ruled out of a system if the correct procedures are followed. One way in which this is evident in general society is the increasing tendency for an immediate outpouring of criticism on social media whenever a person in public office is shown to have made a mistake, along with demands for resignation. Logically, as society moves toward societal and professional promotion of increasing service user involvement in decisions about their care, it should also be moving toward an acceptance of personal responsibility for these decisions. However, it appears that the notion of individual entitlement is, instead, accompanied by a decreased sense of personal responsibility and, conversely, an increased sense of the accountability of others, often expressed in the person of individual public servants (including health care providers).

This may be an expression of a welcome move from the hegemony of professional power and toward an equal valuing and exercise of different kinds of expertise (those of the professional expert, who is valued for his or her professional wisdom, and those of the individual service user, who is an expert in his or her own personal circumstances). However, there is a potentially turbulent space between the welcome early moves in this direction indicated in the article by Kabakian-Khasholian and colleagues (2015) and the suggestion that, at the other extreme, professional experts are increasingly paralyzed by uncertainty and fear, with the result of, in the case of midwives, Midwifery Abdication in the name of service user choice (Jefford \& Jomeen, 2015).

Ultimately, as expressed so eloquently in the study of Young et al. (2015), this phenomenon can lead to burnout because (in this case) midwives struggle with the almost impossible task of trying to protect women and their babies from a system that they see as hostile; upholding women's choice (which might in some cases actually be for technocratic interventions, contrary to at least one version of the midwifery project) while maintaining wise expert practice; and optimizing safety and well-being for mother, baby, and family, all the time assuming that they will be held responsible for any mistake that might occur.

I would suggest that the task of those designing, funding, managing, and working within maternity care and of those receiving care within these services is to accept the notion of uncertainty and to build systems collaboratively around this fact. This is not a reversion to the standard notions of either "no birth is normal until it is over" or "all births are normal until proven otherwise" or of reducing adverse clinical events at all costs versus optimizing the childbirth experience at all costs. Nor is it about prioritizing the knowledge and decision making of one group over that of another. It is a call to build systems that accommodate both/and rather than either/or and that permit those with expertise to use it wisely, in collaboration with service users and with other professional colleagues, based on mutually respectful relationships. The Lancet Quality Maternal and Newborn Care Framework (Renfrew et al., 2014) provides a good basis for starting a conversation with all these stakeholder groups. It is also crucial to identify and understand the mechanism of effect in practices/institutions that are successful in maintaining this creative balance, especially when they are succeeding in contexts where others are not. As the three articles highlighted suggest, reaching an understanding of how expertise can be used wisely in mutually respectful relationships with colleagues and service users may be one of the most important issues of next years if we are to avoid the loss of that which makes the best maternity care good.

Soo Downe Deputy Editor

Research in Childbirth and Health (ReaCH) Group University of Central Lancashire, United Kingdom

\section{REFERENCES}

Benner, P. (2004). Using the Dreyfus model of skill acquisition to describe and interpret skill acquisition and clinical judgment in nursing practice and education. Bulletin of Science, Technology \& Society, 24(3), 188-199.

Dreyfus, S. E., \& Dreyfus, H. L. (1980). A five-stage model of the mental activities involved in directed skill acquisition. Washington, DC: Storming Media.

Jefford, E., \& Jomeen, J. (2015). "Midwifery abdication": A finding from an interpretive study. International Journal of Childbirth, 5(3), 116-125.

Kabakian-Khasholian, T., Shayboub, R., Kanaan, M., Mahfoud, Z., \& El Kak, F. (2015). Promoting women's participation in maternity care in Lebanon. International Journal of Childbirth, 5(3), 166-176.

Renfrew, M. J., McFadden, A., Bastos, M. H., Campbell, J., Channon, A. A., Cheung, N. F., . . Declercq, E. (2014). Midwifery and quality care: Findings from a new evidence-informed maternity care framework. The Lancet, 384(9948), 1129-1145.

Young, C. M., Smythe, L., \& Couper, J. M. (2015). Burnout: Lessons from the lived experience of case loading midwives. International Journal of Childbirth, 5(3), 154-165. 